\title{
Índice de seleção para cultivares de milho com dupla aptidão: minimilho e milho verde
}

\author{
Júlio César DoVale ( $\left.{ }^{(}\right)$; Roberto Fritsche-Neto $\left({ }^{*}\right)$; Paulo Sérgio Lima e Silva $\left({ }^{2}\right)$ \\ (') Universidade Federal de Viçosa, Departamento de Fitotecnia, 36571-000 Viçosa (MG), Brasil. \\ (2) Universidade Federal Rural do Semi-Árido, Departamento de Ciências Vegetais, 59625-900 Mossoró (RN), Brasil. \\ (*) Autor correspondente: rfritscheneto@gmail.com
}

Recebido: 5/abr./2011; Aceito: 29/jun./2011

\begin{abstract}
Resumo
Este trabalho teve por objetivo a elaboração de um índice que permita a seleção acurada de cultivares de milho com aptidão tanto para a produção de minimilho quanto para de milho verde. Os experimentos foram realizados no ano agrícola de 2002/2003 com dez cultivares comerciais de milho em dois experimentos. O primeiro quanto ao rendimento de minimilho e o segundo quanto ao de milho verde, delineados em blocos ao acaso com três repetições. A importância relativa dos caracteres estudados foi estimada por meio do método dos componentes principais e o agrupamento destes foi realizado pela análise de fatores. O seguinte índice foi obtido: I = 0,031 NEM + 0,013 MEM + 0,207 NEV + 0,243 MEV - 0,16 AP - 0,058 MFP, em que, NEM, MEM, NEV, MEV, AP e MFP são o número e a massa de espigas empalhadas de minimilho e de milho verde, altura de planta e massa de pendão fresca respectivamente. Esse índice indicou que híbridos triplos DKB 350, AG 8080 e AG 6690 e o duplo DKB 747 revelaram os melhores desempenhos para as produções de minimilho e de milho verde.
\end{abstract}

Palavras-chave: componentes principais, análise de fatores, Zea mays $L$.

\section{Selection index of maize cultivars with twice fitness: baby corn and green corn}

\section{Abstract}

This study aimed to propose an index for allowing accurate selection of corn hybrids for producing both baby corn and green corn. The experiments were carried out during the 2002/2003 growing season and ten commercial corn cultivars were evaluated in two experiments, the first for evaluating the yield of baby corn and the second for the yield of green corn. Both experiments were designed in randomized blocks, with three replications. The relative importance of traits was estimated by the principal components method and the cluster analysis was carried out. The following index was obtained: I = $0.031 \mathrm{NEM}$ + 0.013 MEM + 0.207 NEV + 0.243 MEV - 0.16 AP - 0.058 MFP, being considered the variables: number and mass of husked ears for baby corn (NEM and MEM) and green corn (NEV and MEV), plant height (AP) and the fresh mass of tassel (MFP). This index indicated that the three-way cross hybrids DKB 350, AG 8080 and AG 6690 and the double-cross hybrids DKB 747 have the best performances for the production of baby corn and green corn.

Key words: principal components, factor analysis, Zea mays L.

\section{INTRODUÇÃO}

A exploração da cultura do milho para produção de milho verde é uma das atividades agrícolas mais importantes do Brasil, especialmente para o Nordeste. As espigas são colhidas com os grãos imaturos com teor de umidade entre $70 \%$ e $80 \%$. Este produto é apreciado em todo o país, sendo consumido in natura ou sob a forma de diversos pratos, ou ainda industrializado e comercializado sob a forma de milho verde enlatado.

Outra opção de exploração da cultura do milho, comum em outros países e que começou a despertar a atenção de pesquisadores brasileiros é a produção de minimilho. O minimilho é a espiga despalhada, colhida de dois a três dias após a exposição dos estilos-estigmas, sem a ocorrência de fertilização. É utilizado na alimentação humana, principalmente nos países asiáticos, in natura ou em conserva. Mostra-se como uma boa alternativa ao pequeno produtor por apresentar boa lucratividade (Almeida et al., 2005) e perspectivas de exportação.

No Brasil ainda náo existem relatos de programas de melhoramento destinado à obtenção de cultivares de milho para a produção de minimilho. Neste contexto, também são poucas as cultivares específicas para produção de milho verde disponíveis no mercado. $\mathrm{Na}$ avaliação dos rendimentos desses produtos são utilizados, frequentemente, cultivares desenvolvidas para a produção de grãos. Todavia, possivelmente, há dentre as cultivares desenvolvidas para produção de grãos aquelas mais aptas para produção de minimilho ou de milho 
verde. A identificação dessas cultivares possibilitaria sua recomendação ao agricultor ou ainda, a utilização como genitores em programas de melhoramento.

A análise de fatores é um método estatístico multivariado que vem sendo aplicado em estudos agronômicos há relativamente pouco tempo, devido às dificuldades que existiam para a realização dos cálculos necessários (GrANATE et al., 2001). Com o advento dos recursos computacionais, o método passou a ser utilizado mais frequentemente (GARBUGLIo et al., 2007). Nesse método, os caracteres inicialmente avaliados são substituídos por um número menor de caracteres latentes, chamados fatores. Estes fatores agrupam os caracteres de forma que haja pouca ou nenhuma variância dentro dos grupos, bem como variação máxima entre grupos (CRUZ e CARNEIRO, 2003). Esse resultado, associado a uma análise de componentes principais, possibilita descartar os caracteres que menos discriminam genótipos e entâo elaborar índices de seleção.

A técnica dos componentes principais tem sido de grande utilidade no melhoramento genético, por permitir simplificar um conjunto de $n$ variáveis em poucos componentes que possuem propriedades de reter o máximo da variação inicialmente disponível e ser independentes entre si (Cruz e Carneiro, 2003). Essa técnica é geralmente utilizada em estudos de diversidade genética, mas no presente estudo teve por finalidade auxiliar na identificação de caracteres que menos contribuem para discriminar genótipos com dupla aptidáo. Geralmente, são caracteres correlacionados com outros considerados no estudo (Granate et al., 2001), ou ainda, os invariantes.

Objetivou-se com este trabalho a elaboração de um índice que permita a seleção acurada de cultivares de milho com aptidáo tanto para a produçáo de minimilho como a de milho verde.

\section{MATERIAL E MÉTODOS}

Os experimentos foram realizados no ano agrícola de 2002/2003 com dez cultivares comerciais de milho desenvolvidas pela empresa Monsanto: DKB 333B e AG 7575 (híbridos simples); DKB 350, AG 8080 e AG 6690 (híbridos triplos); DKB 435, DKB 747, AG 2060, AG 405 e AG 1051 (híbridos duplos). Essas cultivares foram avaliadas em dois experimentos justapostos, delineados em blocos ao acaso, com três repetiçóes. Os experimentos diferiram apenas quanto à finalidade da produção.

O primeiro experimento foi avaliado quanto à produção de minimilho, utilizando-se densidade populacional de 178.571 plantas ha $^{-1}$ (espaçamento $0,80 \mathrm{~m} \mathrm{x} \mathrm{0,07} \mathrm{m).}$ As parcelas foram constituídas por cinco fileiras de seis metros de comprimento, e consideradas como área útil as três fileiras centrais menos as seis plantas de cada extremidade. Foram avaliados o número e a massa de espigas empalhadas e despalhadas, o comprimento e o diâmetro de espigas e as alturas de planta e de espiga.
O segundo experimento foi avaliado quanto à produçáo de milho verde. A densidade de plantio adotada foi a de 50.000 plantas ha ${ }^{-1}$ (espaçamento $1,0 \mathrm{~m} \mathrm{x} \mathrm{0,4}$ $\mathrm{m}$, com duas plantas $\left.\operatorname{cova}^{-1}\right)$. Diferentemente do primeiro experimento, a parcela foi constituída por quatro fileiras de seis metros, e como área útil, consideraram-se as duas fileiras centrais menos as seis plantas de cada extremidade. Foram avaliados o número e a massa de espigas empalhadas e despalhadas, a massa fresca e a seca de pendão e também o número de ramificaçôes do pendão. Para a contabilidade do número e da massa de espigas despalhadas, foram consideradas aquelas que atingiram padrão comercial, isto é, boa sanidade, coloração branco-pérola a amarelo-clara, forma cilíndrica com diâmetro de 0,8 a 1,8 $\mathrm{cm}$, comprimento de 4 a $12 \mathrm{~cm}$ para minimilho e comprimento maior ou igual a $18 \mathrm{~cm}$ para milho verde.

Em ambos os experimentos os tratos culturais referentes à adubação e aos controles de pragas e plantas daninhas foram realizados conforme AlmEida et al., 2005.

Os dados obtidos foram submetidos à análise de variância utilizando-se o seguinte modelo: $Y_{i j}=\mu+g_{i}+r_{j}+\varepsilon_{i j}$, em que, $Y_{i j}$ é observação referente ao $i$-ésimo genótipo na $j$-ésima repetição; $\mu$ a média geral; $g_{\mathrm{i}}$ é efeito do $i$-ésimo genótipo $(i=1,2, \ldots 10) ; r_{j}$ o efeito da $j$-ésima repetição $(j=1$, $2,3)$ e $\varepsilon_{\mathrm{ij}}$ o erro experimental associado à observação $Y_{\mathrm{ij}}$

As estimativas das correlações fenotípicas $\left(r_{\mathrm{f}}\right)$ foram obtidas por meio do coeficiente de Pearson:

$$
\mathrm{r}_{\mathrm{f}}=\frac{\sum_{\mathrm{i}=1}^{\mathrm{n}}\left(\mathrm{x}_{\mathrm{i}}-\overline{\mathrm{x}}\right)\left(y_{\mathrm{i}}-\bar{y}\right)}{\sqrt{\sum_{\mathrm{i}=1}^{\mathrm{n}}\left(\mathrm{x}_{\mathrm{i}}-\overline{\mathrm{x}}\right)^{2} \cdot \sqrt{\sum_{\mathrm{i}=1}^{\mathrm{n}}\left(y_{\mathrm{i}}-\bar{y}\right)^{2}}}} \text { em que, } x_{1}, x_{2}, \ldots, x_{n}
$$

e $y_{1}, y_{2}, \ldots, y_{n}$ são os valores observados para os caracteres tanto no experimento de produção de minimilho como no de milho verde. As estimativas de $r_{f}$ foram testadas a $1 \%$ e $5 \%$ de probabilidade pelo teste t.

A importância relativa dos caracteres estudados foi estimada por meio do método dos componentes principais (SINGH, 1981). Para a eliminação de caracteres optou-se por descartar os que menos contribuíram para a divergência genética entre os híbridos. Desse modo, para a construção do índice foram ignorados os caracteres com os maiores valores de ponderação nos componentes de menores autovalores.

Em seguida, foram realizadas as análises de fatores utilizando-se o seguinte modelo: $X_{\mathrm{j}}=1_{\mathrm{j} 1} \mathrm{~F}_{1}+1_{\mathrm{j} 2} \mathrm{~F}_{2}+\ldots .+1_{\mathrm{jm}} \mathrm{F}_{\mathrm{m}}+\varepsilon_{\mathrm{j}}$, em que, $\mathrm{X}_{\mathrm{j}}$ é a variável estimada em cada parcela com $j=1,2, \ldots v, 1_{\mathrm{jk}}$ é a carga fatorial para a $j$-ésima variável associada ao $k$-ésimo fator, sendo $\mathrm{k}=1,2, \ldots \mathrm{m}, \mathrm{F}_{\mathrm{k}}$ é o $k$-ésimo fator comum e $\varepsilon_{\mathrm{j}}$ é o fator específico associado a $j$-ésima variável. A carga fatorial inicial é dada por: $1_{i \mathrm{k}}=\lambda_{i j}^{2} V_{i j}^{2}$, sendo $\lambda_{\mathrm{ij}}$ o $i$-ésimo autovalor maior que 1 obtido da matriz de correlaçôes fenotípicas 
e $V_{\mathrm{ij}}$ o $j$-ésimo valor do $i$-ésimo vetor, sendo $j$ o número de variáveis e $k$ o número de fatores. A comunalidade é representada por: $\mathrm{C}_{\mathrm{j}}=1_{\mathrm{j} 1}^{2}+1_{\mathrm{j} 2}^{2}+\ldots . .+1_{\mathrm{jm}}^{2}$. $\mathrm{O}$ número de fatores finais considerados para o agrupamento de caracteres foi dado pelo número de autovalores iguais ou superiores a 1. O agrupamento dos caracteres foi feito a partir de cargas fatoriais finais maiores que 0,70 , obtidas após rotação, indicando que esses caracteres possuem alta correlaçáo e podem ser agrupados em um mesmo fator. A extração das cargas fatoriais foi feita pelo método dos componentes principais, e os fatores estabelecidos pelo método de rotaçáo varimax (CRUz e CARNeIro, 2003).

Os escores utilizados na confecção dos índices foram obtidos por meio do sistema de equaçóes: $F_{k}=b_{1 k} X_{1}+b_{2 k} X_{2}+\ldots+b_{v k} X_{v}$, sendo: $\mathrm{b}_{\mathrm{jk}}(\mathrm{k}=1,2, \ldots \mathrm{m}$, $\mathrm{j}=1,2 \ldots \mathrm{v})$ o elemento da matriz $\beta$, dada por: ${ }_{\mathrm{jk}}=\lambda_{i j}^{2} V_{i j}^{2}$, em que: $\Lambda$ é a matriz de dimensóes $\mathrm{m} \mathrm{x} v$ das cargas fatoriais rotacionadas finais e $\beta$ a matriz de dimensão $\mathrm{m} \times \mathrm{v}$ de coeficientes de ponderaçáo dos caracteres para a obtenção dos escores dos fatores.

As análises de variância e o teste de médias foram realizados pelo programa estatístico computacional Statistical Analysis System (SAS) versão 9.1 (SAS InStitute, 2003). As análises remanescentes foram feitas por meio do aplicativo computacional em genética e estatística GENES (Cruz, 2006).

\section{RESULTADOS E DISCUSSÃO}

Os resultados das análises de variância indicaram a existência de diferenças no efeito de híbridos para todos os caracteres de minimilho e milho verde (Tabelas 1 e 2). Além de possuírem estruturas genéticas distintas, as cultivares foram desenvolvidas para a produção de grãos, o que as tornam diferenciadas quanto à produção de minimilho e milho verde, assim como para outros caracteres.

O híbrido triplo DKB 350 foi superior quanto ao número e à massa de espigas despalhadas de minimilho. Outros híbridos que se destacaram quantos a esses caracteres foram AG 8080 e duplo DKB 435 (Tabela 1). O desempenho de algumas cultivares foi satisfatório quanto ao número de espigas, porém houve redução de massa. As diferenças existentes entre os rendimentos de espigas empalhadas e despalhadas decorrem do fato de que nem todas as espigas empalhadas têm o padrão exigido pelo mercado (Almeida et al., 2005). Com relação à produção de milho verde, o híbrido duplo DKB 747 foi o mais produtivo, pois possue maior número e massa de espigas de milho verde comercializáveis, tanto empalhadas como despalhadas (Tabela 2).

Houve correlação significativa e de alta magnitude entre os caracteres que compóem a produção de minimilho e de milho verde (Tabela 3). No entanto, esses componentes revelaram relação negativa com as alturas de planta e de espiga e com os caracteres de dimensáo da espiga. Em geral, as cultivares mais produtivas possuem menor comprimento de espiga. Quanto aos caracteres de milho verde, constatou-se a tendência de as cultivares mais produtivas terem menores valores para os caracteres relativos à dimensão do pendão. Essa característica se deve ao fato de as cultivares modernas possuírem menor pendão, pois esse é um forte dreno que demanda grande quantidade de fotoassimilados para sua formação e manutenção. Desse modo, há relação negativa entre tamanho de pendão e número e massa de espigas (Souza Júnior et al., 1985).

Tabela 1. Resumo das análises de variância e dos testes de médias para os caracteres de dez cultivares de milho, avaliados quanto à produção de minimilho, em Mossoró (RN), no ano agrícola de 2002/2003

\begin{tabular}{|c|c|c|c|c|c|c|c|c|}
\hline \multirow{3}{*}{ Fonte de variação } & \multicolumn{8}{|c|}{ Quadrados Médios } \\
\hline & \multicolumn{2}{|c|}{ Número de espigas ha ${ }^{-1}$} & \multicolumn{2}{|c|}{ Massa de espigas (kg ha-1) } & \multicolumn{2}{|c|}{ Dimensões da espigas (cm) } & \multicolumn{2}{|c|}{ Altura $(\mathrm{cm})$} \\
\hline & Empalhadas & Despalhadas & Empalhadas & Despalhadas & Comprimento & Diâmetro & Planta & Espiga \\
\hline Cultivar & $5321584652 * *$ & $1877567526^{* *}$ & $5748910 * *$ & 172164 ** & $1,63^{* *}$ & $0,0091^{* *}$ & $711,29 *$ & $1084,99 * *$ \\
\hline Resíduo & 592292012 & 296773218 & 912743 & 33233 & 0,0567 & 0,0017 & 346 & 102 \\
\hline \multirow[t]{2}{*}{ CV (\%) } & 20,8 & 36,8 & 21,7 & 41,3 & 2,8 & 3,2 & 10,8 & 11,2 \\
\hline & \multicolumn{8}{|c|}{ Teste de Médias } \\
\hline DKB 333B ${ }^{(1)}$ & 91505 bcd & 46718 bc & 3627 bc & 457 b & 8,76 bc & $1,24 \mathrm{bc}$ & $191 \mathrm{a}$ & $106 a b$ \\
\hline AG $7575^{(1)}$ & $139189 a b$ & 43243 bc & $4719 a b c$ & $403 \mathrm{~b}$ & $9,36 \mathrm{a}$ & $1,26 \mathrm{bc}$ & $167 \mathrm{ab}$ & $73 c$ \\
\hline AG $6690^{(2)}$ & $133691 \mathrm{abc}$ & 39044 bc & 4599 abc & $371 \mathrm{~b}$ & $9,20 \mathrm{ab}$ & $1,28 \mathrm{abc}$ & $176 \mathrm{ab}$ & 88 bc \\
\hline AG $8080^{(2)}$ & 107529 bcd & $53475 a b c$ & $5672 \mathrm{a}$ & $526 a b$ & 7,92 de & 1,26 bc & $176 a b$ & $82 \mathrm{c}$ \\
\hline DKB $350^{(2)}$ & $172393 \mathrm{a}$ & 83765 a & $6100 \mathrm{a}$ & 877 a & $7,76 \mathrm{e}$ & $1,30 \mathrm{abc}$ & $153 a b$ & $73 \mathrm{c}$ \\
\hline AG $1051^{(3)}$ & $87066 \mathrm{~cd}$ & $30309 c$ & 3384 bc & $323 b$ & $8,96 \mathrm{ab}$ & $1,32 \mathrm{ab}$ & $184 \mathrm{ab}$ & $112 \mathrm{a}$ \\
\hline AG $405^{(3)}$ & 80695 d & $24324 \mathrm{c}$ & 2936 c & $186 b$ & $8,88 \mathrm{ab}$ & $1,30 \mathrm{abc}$ & $186 \mathrm{ab}$ & $109 a b$ \\
\hline AG $2060^{(3)}$ & $76448 d$ & 22973 c & 3233 bc & $293 b$ & $9,10 a b$ & $1,36 \mathrm{a}$ & $174 a b$ & 88 bc \\
\hline DKB $747^{(3)}$ & $140723 \mathrm{ab}$ & $56564 \mathrm{abc}$ & 4844 abc & 482 b & $8,34 \mathrm{de}$ & 1,24 bc & $160 \mathrm{ab}$ & $77 \mathrm{c}$ \\
\hline DKB $435^{(3)}$ & $141119 a b$ & $68146 \mathrm{ab}$ & $5008 a b$ & $498 a b$ & $8,06 \mathrm{~cd}$ & $1,22 \mathrm{c}$ & $176 \mathrm{ab}$ & 92 abc \\
\hline Média Geral & 117026 & 46856 & 4412 & 441 & 8,63 & 1,28 & 173 & 90 \\
\hline
\end{tabular}

** e ${ }^{*}$ significativos a 1 e $5 \%$ de probabilidade pelo teste $\mathrm{F}$ respectivamente. $(1,2,3)=$ Híbrido simples, triplo e duplo respectivamente.

Médias seguidas pela mesma letra náo diferem pelo teste de Tukey $(\mathrm{p}<0,05)$. 
Tabela 2. Resumo das análises de variância e dos testes de médias para os caracteres de dez cultivares de milho, avaliados quanto à produção de milho verde, em Mossoró (RN), no ano agrícola de 2002/2003

\begin{tabular}{|c|c|c|c|c|c|c|c|}
\hline \multirow{3}{*}{ Fonte de variação } & \multicolumn{6}{|c|}{ Quadrados Médios } & \multirow{3}{*}{$\begin{array}{l}\text { Número de } \\
\text { ramificaçõe } \\
\text { do pendão }\end{array}$} \\
\hline & \multicolumn{2}{|c|}{ Número de espigas ha-1 } & \multicolumn{2}{|c|}{ Massa de espigas (kg ha-1) } & \multicolumn{2}{|c|}{ Massa de pendão (g) } & \\
\hline & Empalhadas & Despalhadas & Empalhadas & Despalhadas & Fresca & Seca & \\
\hline Cultivar & $133408554^{* *}$ & $136570983^{*}$ & $13372827^{* *}$ & $6073579 * *$ & $230,83^{* *}$ & $35,77^{* *}$ & $15,05^{* *}$ \\
\hline Resíduo & 29612394 & 47491194 & 2703320 & 1506093 & 15,88 & 2,42 & 2,63 \\
\hline \multirow[t]{2}{*}{ CV (\%) } & 16,1 & 29,9 & 18,0 & 28,7 & 10,0 & 8,2 & 14,6 \\
\hline & \multicolumn{7}{|c|}{ Teste de Médias } \\
\hline DKB 333B ${ }^{(1)}$ & 26682 bc & $17430 a b$ & $6932 c$ & 2951 b & $43 a b$ & $21 \mathrm{abc}$ & $12 \mathrm{abc}$ \\
\hline AG $7575^{(1)}$ & $32104 a b c$ & $23415 a b$ & $7680 \mathrm{bc}$ & $3629 b$ & $29 d$ & $14 \mathrm{e}$ & $8 c$ \\
\hline AG $6690^{(2)}$ & $37675 a b$ & $27227 a b$ & $10659 a b c$ & $4998 a b$ & $37 \mathrm{bcd}$ & 18 cde & $9 c$ \\
\hline AG $8080^{(2)}$ & 39066 a & $17902 a b$ & $10958 \mathrm{ab}$ & 3508 b & $31 \mathrm{~cd}$ & 16 de & $10 \mathrm{bc}$ \\
\hline DKB $350^{(2)}$ & $33878 \mathrm{abc}$ & $27596 a b$ & $8945 a b c$ & $5232 a b$ & $36 \mathrm{bcd}$ & 18 cde & 11 bc \\
\hline AG $1051^{(3)}$ & $24113 c$ & 15496 b & 6998 c & 3105 b & 39 bc & 19 bcd & $11 \mathrm{abc}$ \\
\hline AG $405^{(3)}$ & $35817 \mathrm{ab}$ & $20876 a b$ & $9874 a b c$ & $4098 a b$ & $44 a b$ & $21 \mathrm{ab}$ & $14 \mathrm{a}$ \\
\hline AG $2060^{(3)}$ & $32052 \mathrm{abc}$ & $23613 a b$ & $9317 a b c$ & $4957 a b$ & $49 a$ & $24 \mathrm{a}$ & $12 a b c$ \\
\hline DKB $747^{(3)}$ & 39961 a & $32194 \mathrm{a}$ & $11630 \mathrm{a}$ & $6430 \mathrm{a}$ & $49 a$ & $21 \mathrm{abc}$ & $13 a b$ \\
\hline DKB $435^{(3)}$ & $36026 a b$ & $25000 a b$ & $8709 a b c$ & $3798 a b$ & $38 \mathrm{bc}$ & $18 \mathrm{bcd}$ & $11 \mathrm{bc}$ \\
\hline Média Geral & 33737 & 23075 & 9161 & 4271 & 39,5 & 19,00 & 11,14 \\
\hline
\end{tabular}

** $\mathrm{e}^{*}$ significativos a 1 e $5 \%$ de probabilidade pelo teste $\mathrm{F}$ respectivamente. $(1,2 e 3)=$ Híbrido simples, triplo e duplo respectivamente.

Médias seguidas pela mesma letra năo diferem pelo teste de Tukey $(\mathrm{P}<0,05)$.

Tabela 3. Coeficientes de correlaçôes fenotípicas de Pearson $\left(r_{\mathrm{f}}\right)$ entre caracteres de dez cultivares de milho, avaliados quanto à produção de minimilho e milho verde, em Mossoró (RN), no ano agrícola de 2002/2003

\begin{tabular}{|c|c|c|c|c|c|c|c|c|c|c|c|c|c|c|c|}
\hline \multirow{4}{*}{ Caracteres } & \multicolumn{8}{|c|}{ Minimilho } & \multicolumn{7}{|c|}{ Milho verde } \\
\hline & \multicolumn{2}{|c|}{$\begin{array}{c}\text { Número de } \\
\text { espigas }\end{array}$} & \multicolumn{2}{|c|}{$\begin{array}{l}\text { Massa de } \\
\text { espigas }\end{array}$} & \multicolumn{2}{|c|}{ Altura } & \multicolumn{2}{|c|}{$\begin{array}{l}\text { Dimensões } \\
\text { da espiga }\end{array}$} & \multicolumn{2}{|c|}{$\begin{array}{c}\text { Número de } \\
\text { espigas }\end{array}$} & \multicolumn{2}{|c|}{$\begin{array}{l}\text { Massa de } \\
\text { espigas }\end{array}$} & \multicolumn{2}{|c|}{$\begin{array}{l}\text { Massa de } \\
\text { pendão }\end{array}$} & \multirow{3}{*}{$\begin{array}{l}\text { Número de } \\
\text { ramificações } \\
\text { do pendão } \\
\text { (NRP) }\end{array}$} \\
\hline & Empa. & Desp. & Empa. & Desp. & Planta & Espiga & Comp. & Diâm. & Empa. & Desp. & Empa. & Desp. & Fresca & Seca & \\
\hline & (NEM) & (NDM) & (MEM) & (MDM) & (AP) & (AE) & (CEM) & (DEM) & (NEV) & (NDV) & (MEV) & (MDV) & (MFP) & (MSP) & \\
\hline NEM & - & $0,84^{* *}$ & $0,85^{* *}$ & $0,77^{* *}$ & $-0,83^{* *}$ & $-0,75^{* *}$ & $-0,46$ & $-0,45$ & 0,43 & $0,70^{*}$ & 0,22 & 0,45 & $-0,41$ & $-0,59$ & $-0,45$ \\
\hline NDM & & & $0,87^{* *}$ & $0,93^{* *}$ & $-0,56$ & $-0,57$ & $-0,81^{* *}$ & $-0,54$ & 0,31 & 0,43 & 0,11 & 0,23 & $-0,22$ & $-0,37$ & $-0,20$ \\
\hline PEM & & & & $0,85^{* *}$ & $-0,70^{*}$ & $-0,78^{* *}$ & $-0,70^{*}$ & $-0,45$ & 0,51 & 0,43 & 0,34 & 0,28 & $-0,54$ & $-0,64^{*}$ & $-0,52$ \\
\hline PDM & & & & & $-0,61$ & $-0,60$ & $-0,76^{* *}$ & $-0,27$ & 0,17 & 0,34 & 0,05 & 0,24 & $-0,32$ & $-0,38$ & $-0,33$ \\
\hline AP & & & & & & $0,86^{* *}$ & 0,28 & 0,01 & $-0,54$ & $-0,84^{* *}$ & $-0,48$ & $-0,78^{* *}$ & 0,41 & 0,48 & 0,51 \\
\hline $\mathrm{AE}$ & & & & & & & 0,31 & 0,19 & $-0,56$ & $-0,67^{*}$ & $-0,43$ & $-0,56$ & 0,52 & 0,57 & $0,64^{*}$ \\
\hline CEM & & & & & & & & 0,36 & $-0,39$ & $-0,18$ & $-0,30$ & $-0,17$ & 0,02 & 0,08 & $-0,15$ \\
\hline DEM & & & & & & & & & $-0,33$ & $-0,19$ & $-0,09$ & 0,11 & 0,21 & 0,37 & 0,09 \\
\hline NEV & & & & & & & & & & $0,65^{*}$ & $0,92^{* *}$ & 0,61 & $-0,17$ & $-0,24$ & $-0,06$ \\
\hline NDV & & & & & & & & & & & 0,58 & $0,90^{* *}$ & $-0,02$ & $-0,14$ & $-0,16$ \\
\hline PEV & & & & & & & & & & & & $0,71^{*}$ & $-0,14$ & $-0,12$ & $-0,05$ \\
\hline PDV & & & & & & & & & & & & & 0,02 & 0,00 & $-0,08$ \\
\hline MFP & & & & & & & & & & & & & & $0,96^{* *}$ & $0,81^{* *}$ \\
\hline MSP & & & & & & & & & & & & & & & $0,78^{* *}$ \\
\hline
\end{tabular}

$\mathrm{Na}$ análise por meio de componentes principais, o percentual de variância acumulada pelos três primeiros componentes foi de $82,48 \%$ (Tabela 4 ), considerado como suficiente para interpretação dos dados com acurácia (BENIN et al., 2009; Nascimento et al., 2009). Assim, observando a análise dos elementos dos dez últimos autovetores, ou seja, do último até aquele em que o valor do autovetor obtido da matriz de correlação é inferior a 0,7 , foram identificados o comprimento e o diâmetro de espigas de minimilho e a altura de espiga como caracteres passíveis de descarte.
O comprimento e o diâmetro da espiga de minimilho são passíveis de descarte pela pouca variância, devido ao fato do ponto fenológico da colheita ser definido, assim como o padrão comercial exigido. $\mathrm{O}$ descarte da altura de espiga se justifica pela correlaçáo alta e significativa que esse caráter possui com a altura de planta (Tabela 3). Assim, a diferença de desempenho entre os híbridos para produção de minimilho está relacionada, principalmente, com a prolificidade deles. $\mathrm{O}$ mesmo não pode ser considerado para produção de milho verde. 
Tabela 4. Estimativas dos autovalores e da fração cumulativa da variância explicada pelos componentes principais, obtidos da matriz de correlação entre caracteres de cultivares de milho, avaliados quanto à produção de minimilho, em Mossoró (RN), no ano agrícola de 2002/2003

\begin{tabular}{lccccccccc}
$\lambda_{j}$ & $\begin{array}{c}\lambda_{j}(\%) \\
\text { acumulado }\end{array}$ & \multicolumn{2}{c}{ Número de espigas } & \multicolumn{2}{c}{ Massa de espigas } & \multicolumn{2}{c}{ Dimensões da espiga } & \multicolumn{1}{c}{ Altura } \\
\cline { 3 - 10 } & Empalhadas & Despalhadas & Empalhadas & Despalhadas & Comprimento & Diâmetro & \multicolumn{1}{c}{ Planta } & Espiga \\
\hline 7,422 & 49,481 & $-0,335$ & $-0,292$ & $-0,340$ & $-0,283$ & 0,205 & 0,147 & 0,324 & 0,325 \\
\hline 2,758 & 67,871 & $-0,061$ & $-0,096$ & $-0,136$ & $-0,145$ & $-0,036$ & 0,142 & $-0,123$ & $-0,006$ \\
\hline 2,191 & 82,481 & $-0,082$ & $-0,386$ & $-0,138$ & $-0,302$ & 0,488 & 0,252 & $-0,173$ & $-0,162$ \\
\hline 1,249 & 90,806 & 0,146 & 0,092 & $-0,051$ & 0,281 & 0,105 & 0,520 & $-0,287$ & $-0,109$ \\
\hline 0,778 & 95,995 & $-0,309$ & $-0,061$ & 0,167 & 0,190 & $-0,416$ & 0,603 & 0,008 & $-0,024$ \\
\hline 0,271 & 97,801 & 0,219 & 0,032 & $-0,183$ & 0,010 & $-0,079$ & 0,115 & $-0,153$ & 0,577 \\
\hline 0,181 & 99,009 & 0,314 & $-0,031$ & 0,151 & $-0,234$ & 0,129 & 0,332 & $-0,160$ & $-0,222$ \\
\hline 0,114 & 99,772 & 0,301 & 0,023 & 0,299 & $-0,038$ & 0,143 & 0,113 & $-0,113$ & 0,617 \\
\hline 0,034 & 99,997 & $-0,021$ & 0,069 & $-0,120$ & 0,633 & 0,521 & 0,009 & 0,111 & 0,092 \\
\hline $3,11 \times 10^{-4}$ & 99,999 & 0,054 & 0,429 & $-0,075$ & $-0,124$ & 0,009 & 0,352 & 0,686 & 0,000 \\
\hline 0 & 99,999 & $-0,187$ & 0,007 & 0,264 & $-0,085$ & $-0,002$ & 0,000 & 0,038 & 0,195 \\
\hline 0 & 99,999 & 0,184 & 0,169 & 0,249 & $-0,408$ & 0,000 & 0,013 & $-0,008$ & 0,008 \\
\hline 0 & 99,999 & $-0,560$ & $-0,079$ & 0,407 & 0,048 & 0,007 & $-0,001$ & $-0,151$ & 0,176 \\
\hline 0 & 99,999 & $-0,327$ & 0,633 & $-0,417$ & $-0,194$ & 0,021 & 0 & $-0,444$ & 0,067 \\
\hline $3,8 \times 10^{-6}$ & 100 & 0,177 & $-0,342$ & $-0,424$ & 0,084 & $-0,469$ & 0,021 & $-0,040$ & 0,108 \\
\hline
\end{tabular}

Tabela 5. Estimativas dos autovalores e da fração cumulativa da variância explicada pelos componentes principais, obtidos da matriz de correlação entre caracteres de cultivares de milho, avaliados quanto à produção de milho verde, em Mossoró (RN), no ano agrícola de 2002/2003

\begin{tabular}{|c|c|c|c|c|c|c|c|c|}
\hline \multirow[b]{2}{*}{$\lambda_{j}$} & \multirow{2}{*}{$\begin{array}{c}\lambda_{j}(\%) \\
\text { acumulado }\end{array}$} & \multicolumn{2}{|c|}{ Número de espigas } & \multicolumn{2}{|c|}{ Massa de espigas } & \multicolumn{2}{|c|}{ Massa de pendão } & \multirow{2}{*}{$\begin{array}{l}\text { Número de } \\
\text { ramificações } \\
\text { do pendão }\end{array}$} \\
\hline & & Empalhadas & Despalhadas & Empalhadas & Despalhadas & Fresca & Seca & \\
\hline 7,422 & 49,481 & $-0,235$ & $-0,261$ & $-0,184$ & $-0,211$ & 0,197 & 0,234 & 0,196 \\
\hline 2,758 & 67,871 & 0,317 & 0,343 & 0,382 & 0,430 & 0,362 & 0,359 & 0,320 \\
\hline 2,191 & 82,481 & 0,066 & 0,097 & 0,158 & 0,162 & $-0,322$ & $-0,252$ & $-0,381$ \\
\hline 1,249 & 90,806 & $-0,460$ & 0,150 & $-0,400$ & 0,190 & 0,185 & 0,203 & $-0,090$ \\
\hline 0,778 & 95,995 & 0,095 & $-0,393$ & 0,312 & $-0,037$ & $-0,193$ & 0,016 & $-0,027$ \\
\hline 0,271 & 97,801 & $-0,126$ & 0,066 & 0,018 & 0,230 & $-0,362$ & $-0,384$ & 0,436 \\
\hline 0,181 & 99,009 & 0,373 & $-0,045$ & $-0,219$ & $-0,464$ & 0,129 & $-0,168$ & 0,415 \\
\hline 0,114 & 99,772 & 0,080 & $-0,050$ & 0,240 & $-0,180$ & 0,326 & 0,085 & $-0,425$ \\
\hline 0,034 & 99,997 & 0,332 & $-0,013$ & 0,055 & $-0,121$ & $-0,263$ & 0,270 & 0,129 \\
\hline $3,11 \times 10^{-4}$ & 99,999 & 0,081 & 0,373 & 0,004 & 0,021 & $-0,011$ & $-0,174$ & $-0,145$ \\
\hline 0 & 99,999 & 0,466 & $-0,188$ & $-0,603$ & 0,471 & $-0,016$ & 0,009 & $-0,106$ \\
\hline 0 & 99,999 & $-0,129$ & 0,021 & 0,002 & $-0,024$ & $-0,549$ & 0,622 & 0,057 \\
\hline 0 & 99,999 & $-0,080$ & 0,588 & $-0,090$ & $-0,282$ & $-0,070$ & $-0,065$ & 0,099 \\
\hline 0 & 99,999 & 0,157 & $-0,090$ & $-0,007$ & $-0,164$ & 0,004 & 0,003 & $-0,141$ \\
\hline $3,8 \times 10^{-6}$ & 100 & 0,278 & 0,302 & $-0,241$ & $-0,251$ & $-0,162$ & 0,186 & $-0,284$ \\
\hline
\end{tabular}

Pela análise de fatores buscou-se obter fatores relacionados simultaneamente com os caracteres que compóem tanto a produção de minimilho como de milho verde. Assim, utilizaram-se os três primeiros autovalores para agrupamento dos caracteres, pois estes absorveram mais de $80 \%$ da variação total (Tabelas 4 e 5). As comunalidades, que representam a proporção da variância do caráter padronizado, são de valores iguais ou superiores a 0,7 , com exceção do diâmetro de espigas de minimilho $(0,3542)$. Valores de comunalidades superiores a 0,64 têm sido aceitos como razoáveis, pois equivalem a uma correlação próxima de 0,80 entre a variável padronizada $\left(\mathrm{X}_{\mathrm{H}}\right)$ e a parte comum que explica esta variável (Z) (GARbuglio et al., 2007). Consequentemente, a discriminaçáo do desempenho dos genótipos com base no diâmetro da espiga de minimilho não é adequada, provavelmente pela pouca variância representada por esse caráter, como mencionado, ratificando os resultados obtidos pela análise de componentes principais.

Com base nos sinais e nas magnitudes das cargas fatoriais finais, constatou-se a formação de seis grupos de caracteres (Tabela 6). É possível verificar que, em cada grupo formado, as correlaçôes entre os caracteres que os compóem são de média a alta magnitude. Dessa forma, é possível desconsiderar aqueles caracteres que são de difícil mensuração e/ou redundantes dentro de cada grupo, como: número e massa de espigas de minimilho despalhadas (grupo 1); número e massa de 
Tabela 6. Comunalidade, cargas fatoriais iniciais e finais, estimadas com base em 15 caracteres de dez cultivares de milho avaliados quanto à produção de minimilho e milho verde, em Mossoró (RN), no ano agrícola de 2002/2003

\begin{tabular}{|c|c|c|c|c|c|c|c|c|c|}
\hline \multirow{3}{*}{$\begin{array}{l}\text { Finalidade da } \\
\text { produção }\end{array}$} & \multirow{3}{*}{ Caráter avaliado } & \multirow{3}{*}{$\begin{array}{l}\text { N. }{ }^{\circ} \text { do } \\
\text { grupo }\end{array}$} & \multirow{3}{*}{ Comunalidade } & \multirow{2}{*}{\multicolumn{3}{|c|}{$\begin{array}{c}\text { Cargas iniciais } \\
\text { Fatores }\end{array}$}} & \multirow{2}{*}{\multicolumn{3}{|c|}{$\begin{array}{c}\text { Cargas finais } \\
\text { Fatores }\end{array}$}} \\
\hline & & & & & & & & & \\
\hline & & & & 1 & 2 & 3 & 1 & 2 & 3 \\
\hline \multirow{8}{*}{ Minimilho } & Número de espigas empalhadas & \multirow{4}{*}{1} & 0,858 & $-0,913$ & $-0,100$ & $-0,121$ & $-0,439$ & 0,438 & $-0,688$ \\
\hline & Número de espigas despalhadas & & 0,986 & $-0,796$ & $-0,159$ & $-0,572$ & $-0,145$ & 0,195 & $-0,963$ \\
\hline & Massa de espigas empalhadas & & 0,951 & $-0,927$ & $-0,226$ & $-0,204$ & $-0,474$ & 0,329 & $-0,786$ \\
\hline & Massa de espigas despalhadas & & 0,850 & $-0,770$ & $-0,240$ & $-0,447$ & $-0,259$ & 0,154 & $-0,871$ \\
\hline & Comprimento da espiga & 2 & 0,835 & 0,557 & $-0,059$ & 0,722 & $-0,200$ & $-0,172$ & 0,875 \\
\hline & Diâmetro da espiga & 3 & 0,354 & 0,400 & 0,235 & 0,373 & 0,118 & 0,043 & 0,582 \\
\hline & Altura de planta & \multirow{2}{*}{4} & 0,884 & 0,881 & $-0,205$ & $-0,256$ & 0,461 & $-0,754$ & 0,321 \\
\hline & Altura de espiga & & 0,842 & 0,886 & $-0,011$ & $-0,239$ & 0,574 & $-0,607$ & 0,379 \\
\hline \multirow{7}{*}{ Milho verde } & Número de espigas empalhadas & & 0,700 & $-0,639$ & 0,526 & 0,098 & $-0,045$ & 0,805 & $-0,214$ \\
\hline & Número de espigas despalhadas & & 0,850 & $-0,711$ & 0,570 & 0,143 & $-0,080$ & 0,893 & $-0,215$ \\
\hline & Massa de espigas empalhadas & & 0,709 & $-0,502$ & 0,635 & 0,233 & 0,009 & 0,842 & $-0,003$ \\
\hline & Massa de espigas despalhadas & & 0,896 & $-0,574$ & 0,714 & 0,239 & 0,019 & 0,946 & $-0,026$ \\
\hline & Massa fresca do pendão & \multirow{3}{*}{6} & 0,876 & 0,536 & 0,602 & $-0,476$ & 0,928 & $-0,007$ & 0,118 \\
\hline & Massa seca do pendão & & 0,900 & 0,638 & 0,596 & $-0,373$ & 0,912 & $-0,043$ & 0,258 \\
\hline & Número de ramificações do pendão & & 0,886 & 0,533 & 0,532 & $-0,564$ & 0,937 & $-0,083$ & 0,036 \\
\hline
\end{tabular}

espigas verdes despalhadas (grupo 5); altura de espiga (grupo 4) e massa de pendão seca e o número de ramificações do pendão (grupo 6).

$\mathrm{Na}$ seleção simultânea de caracteres, diversos índices foram propostos ao longo dos anos, sendo a eficiência desses, variável, de acordo com os objetivos e o germoplasma do programa de melhoramento (ARnhold e GonÇALVES, 2009; Vilarinho et al., 2003). Para a construção do índice de seleção proposto neste trabalho foram desconsiderados os caracteres de mais difícil mensuração, os redundantes e os não adequados para a discriminação de genótipos, como por exemplo, o diâmetro de espigas de minimilho. Para a seleção dos melhores genótipos com as duas aptidões, foram utilizados coeficientes de ponderação dos caracteres a partir dos escores obtidos em cada fator. Dentre estes, constatou-se que o Fator 2 proporcionou o índice mais aceitável, pois atribuiu maiores pesos aos caracteres de maior importância para produção: $\mathrm{I}_{2}=0,031 \mathrm{NEM}$ + 0,013 MEM + 0,207 NEV + 0,243 MEV - 0,16 AP - 0,058 MFP, em que, NEM, MEM, NEV, MEV, AP e MFP, correspondem ao número e à massa de espigas empalhadas de minimilho e de milho verde, altura de planta e massa de pendão fresca respectivamente.

A partir do índice obtido, verificou-se que os híbridos triplos DKB 350, AG 8080 e AG 6690 e o duplo DKB 747 proporcionaram os maiores escores. Logo, essas cultivares podem ser utilizadas tanto para a produçáo de minimilho como para a de milho verde.

Os resultados deste trabalho permitem reiterar os resultados observados por Ceron-Rojas e SahagunCastellanos (2005), de que as análises multivariadas permitem: a) descartar caracteres inadequados para discriminação de genótipos; b) agrupar caracteres altamente correlacionados com outros estudados permitindo reduzi-los a poucos; c) confeccionar índices de seleção acurados com base em caracteres adequados para a seleção de genótipos com dupla aptidão e sem o estabelecimento de pesos econômicos.

\section{CONCLUSÃO}

A técnica da análise de fatores, associada à dos componentes principais, permitiu a construção do seguinte índice de seleção para obtenção de genótipos de milho com aptidão para produçáo de minimilho e de milho verde: $\mathrm{I}=0,031$ $\mathrm{NEM}+$ 0,013 MEM + 0,207 NEV + 0,243 MEV - 0,16 AP - 0,058 MFP, em que, NEM, MEM, NEV, MEV, AP e MFP são o número e a massa de espigas empalhadas de minimilho e de milho verde, altura de planta e massa de pendão fresca respectivamente. Por meio deste índice, os híbridos triplos DKB 350, AG 8080 e AG 6690 e o duplo DKB 747 proporcionam desempenhos superiores para a produção de minimilho e de milho verde.

\section{REFERÊNCIAS}

ALMEIDA, I.P.C.; SILVA, P.S.L.; NEGREIROS, M.Z.; BARBOSA, Z. Baby corn, green ear, and grain yield of corn cultivars. Horticultura Brasileira, v.23, p.960-964, 2005.

ARNHOLD, E.; SILVA, R.G. Efficiencies on the index of selection. Bioscience Journal, v.25, p.76-82, 2009.

BENIN, G.; SILVA, G.O.; PAGLIOSA, E.S.; LEMES, C.; SIGNORINI, A.; BECHE, E.; CAPELIN, M.A. Capacidade de combinação em genótipos de trigo estimada por meio de análise multivariada. Pesquisa Agropecuária Brasileira, v.44, p.11451151, 2009. 
CERON-ROJAS, J.J.; SAHAGUN-CASTELLANOS, J. A selection index based on principal components. Agrociencia, v.39, p.667-677, 2005.

CRUZ, C.D. Programa Genes: biometria. Viçosa: UFV, 2006. 382p.

CRUZ, C.D.; CARNEIRO, P.C.S. Modelos biométricos aplicados ao melhoramento genético. Viçosa: UFV, 2003. v.2, 585p.

GARBUGLIO, D.D.; GERAGE, A.C.; ARAÚJO, P.M.; FONSECA JUNIOR, N.S.; SHIOGA, P.S. Análise de fatores e regressão bissegmentada em estudos de estratificação ambiental e adaptabilidade em milho. Pesquisa Agropecuária Brasileira, v.42, p.183-191, 2007.

GRANATE, M.J.; CRUZ, C.D.; CECON, P.R.; PACHECO, C.A.P. A análise de fatores na predição de ganhos por seleçáo em milho (Zea mays L.). Acta Scientiarum Agronomy, v.23, p.1271-1279, 2001.
NASCIMENTO, M.; CRUZ, C.D.; CAMPANA, A.C.M.; TOMAZ, R.S.; SALGADO, C.C.; FERREIRA, R.P. Alteração no método centroide de avaliação da adaptabilidade genotípica. Pesquisa Agropecuária Brasileira, v.44, p.263-269, 2009.

Sas Institute, SAS/STAT software versão 9.1, Cary, 2003.

SINGH, D. The relative importance of characters affecting genetic divergence. The Indian Journal of Genetic and Plant Breeding, v.41, p.237-245, 1981.

SOUZA JÚNIOR, C.L.; GERALDI, I.O.; ZINSLY, J.R. Influence of tassel size on the expression of prolificacy in maize. Maydica, v.30, p.321-328, 1985.

VILARINHO, A.A.; VIANA, J.M.S.; SANTOS, J.F.; CÂMARA, T.M.M. Eficiência da seleçáo de progênies $S_{1}$ e $S_{2}$ de milho-pipoca, visando à produção de linhagens. Bragantia, v.62, p.9-17, 2003. 